Review Article

\title{
Granulocyte Colony-Stimulating Factor and Its Potential Application for Skeletal Muscle Repair and Regeneration
}

\author{
Craig R. Wright, ${ }^{1}$ Alister C. Ward, ${ }^{2}$ and Aaron P. Russell ${ }^{1}$ \\ ${ }^{1}$ Institute for Physical Activity and Nutrition (IPAN), School of Exercise and Nutrition Sciences, Deakin University, Geelong, \\ VIC, Australia \\ ${ }^{2}$ Centre for Molecular and Medical Research, School of Medicine, Deakin University, Waurn Ponds, VIC, Australia
}

Correspondence should be addressed to Craig R. Wright; craig.wright@deakin.edu.au

Received 16 August 2017; Accepted 10 October 2017; Published 7 December 2017

Academic Editor: Shin-ichi Yokota

Copyright ( 2017 Craig R. Wright et al. This is an open access article distributed under the Creative Commons Attribution License, which permits unrestricted use, distribution, and reproduction in any medium, provided the original work is properly cited.

Granulocyte colony-stimulating factor (G-CSF) was originally discovered in the context of hematopoiesis. However, the identification of the G-CSF receptor (G-CSFR) being expressed outside the hematopoietic system has revealed wider roles for G-CSF, particularly in tissue repair and regeneration. Skeletal muscle damage, including that following strenuous exercise, induces an elevation in plasma G-CSF, implicating it as a potential mediator of skeletal muscle repair. This has been supported by preclinical studies and clinical trials investigating G-CSF as a potential therapeutic agent in relevant disease states. This review focuses on the growing literature associated with G-CSF and G-CSFR in skeletal muscle under healthy and disease conditions and highlights the current controversies.

\section{Granulocyte Colony-Stimulating Factor (G-CSF)}

Granulocyte colony-stimulating factor (G-CSF) is a glycoprotein first recognized for its ability to facilitate the formation of neutrophilic granulocyte colonies in soft agar from bone marrow cells $[1,2]$. Endogenous production of G-CSF is largely stimulated by infection and tissue damage. Although numerous cell types can produce G-CSF, it is primarily induced by immune cells such as macrophages as well as the endothelium $[3,4]$ and binds to a cognate receptor. Marketed as Neupogen ${ }^{\circledR}$ (filgrastim) (AMGEN ${ }^{\circledR}$ ), recombinant G-CSF was introduced into phase I clinical trials in the mid-1980s, to restore neutrophil numbers in patients receiving chemotherapy [5]. The primary symptom for G-CSF administration is immunodeficiency, particularly neutropenia. It is used to treat severe chronic neutropenia (SCN) and neutrophil deficiencies associated with leukemia and other hematopoietic disorders [6-9], as well as neutropenia induced by chemotherapy [10-12], following bone marrow ablation prior to transplantation $[13,14]$, or neutrophil deficiencies caused by antiviral medications [15].
Recombinant G-CSF is administered subcutaneously or intravenously with maximal serum concentrations around $40-50 \mathrm{ng} / \mathrm{ml}$ being reached after 2-8 hours [16]. At low doses, G-CSF is able to mobilize peripheral blood progenitor cells, which has seen its application used for blood banking procedures that have largely removed the need for bone marrow transplantation $[17,18]$.

\section{Granulocyte Colony-Stimulating Factor Receptor (G-CSFR) and Intracellular Signalling Pathways}

G-CSF's biological activity is mediated through a specific cognate receptor (G-CSFR) that belongs to the class I cytokine receptor superfamily $[3,19,20]$. The G-CSFR has a large glycosylated extracellular region that includes an $\mathrm{N}$-terminal immunoglobulin- (Ig-) like domain, a cytokine receptor homology $(\mathrm{CRH})$ domain, and three fibronectin type III (FBN) domains [21] (Figure 1). The CRH is an approximately 200 amino acid sequence that consists of four conserved cysteine residues and a Trp-Ser-X-Trp-Ser (WSXWS) motif, a hallmark of the class I cytokine receptors 


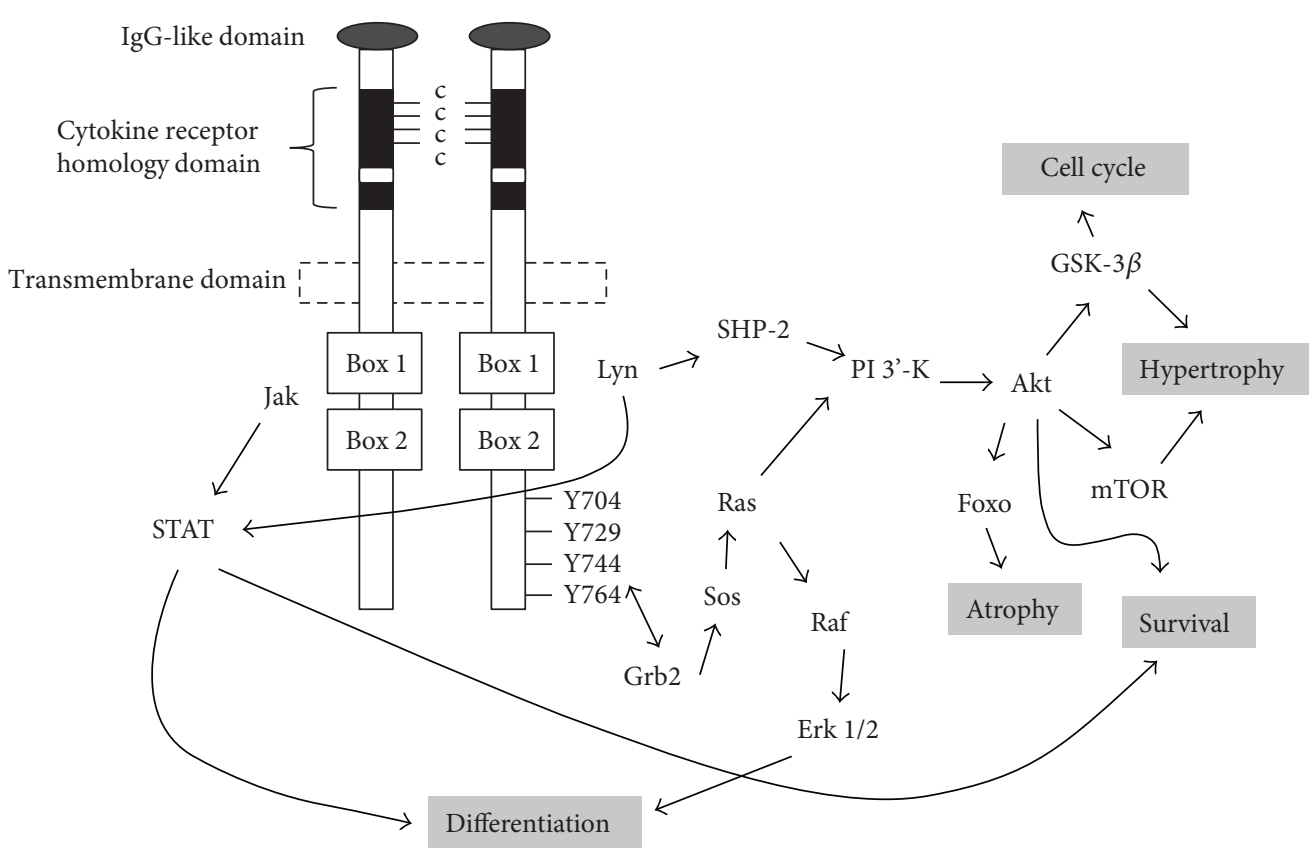

FIgURE 1: Schematic representation of the G-CSF and intracellular signalling pathways.

[22]. The CRH domain is involved in ligand recognition that is essential for the dimerization of two or more receptor chains and crucial for signal transduction [23]. The Ig and FBN domains contribute to receptor stability. The extracellular domain is separated from the intracellular domain by a short transmembrane sequence. Intracellularly, the membrane-proximal domain contains conserved Box 1 and Box 2 motifs and a tyrosine residue (Y704) important for proliferative signalling [24] (Figure 1). The distal domain contains a less conserved Box 3 motif associated with receptor trafficking [25] and three additional tyrosine residues (Y729, Y744, and Y764) important for proliferation, differentiation, and survival $[24,26]$ (Figure 1). Studies conducted in neutrophils show that only a few receptors need to be occupied by G-CSF to elicit a maximal biological response [27, 28].

Ligation of G-CSF causes conformational changes in G-CSFR that activates members of the Janus kinase family (JAK1, JAK2, and TYK2), cytoplasmic tyrosine kinases associated with Box 1 [24] (Figure 1). Activated JAKs subsequently phosphorylate the G-CSFR complex, creating docking sites for a variety of signalling molecules. This includes members of the STAT family of transcription factors $[29,30]$, particularly STAT3 and to a lesser extent STAT1 and STAT5 [31], which homo- or heterodimerize and translocate to the nucleus where they bind DNA and activate the transcription of responsive genes [32]. Also recruited are members of the Src family of tyrosine kinases, particularly Lyn and Hck, which activate phosphatidylinositol-3-kinase $(\mathrm{PI} 3 \mathrm{~K})[33,34]$ that in turn phosphorylates and activates Akt [35, 36] (Figure 1). Akt, a serine/threonine protein kinase, plays a role in many cellular processes such as glucose metabolism, cell survival, cell proliferation, and protein synthesis via numerous downstream targets [37-40] and is a major signalling pathway in skeletal muscle. Recruitment of a Grb2/Shc complex to Y704 and Y764 leads to activation of the MAPK family members, ERK1 and ERK/2, via the RAS/RAF/MEK pathway [41] (Figure 1). ERK1/2 translocates to the nucleus and activates a wide range of transcription factors and phosphorylates the protein kinase $\mathrm{p} 90$ ribosomal S6 kinase (p90RSK) to initiate protein synthesis [42].

These signalling pathways appear conserved in many tissues now postulated to express a functional G-CSFR. For example, PI3K/Akt pathways are activated by G-CSF in cultured neurons [43]. JAK/STAT signalling pathways [44] and PI3K pathways [45] are activated following myocardial infarction and/or heart failure, and similarly, JAK/STAT signalling pathways are activated in cultured cardiomyocytes [44]. In skeletal muscle, JAK/STAT and PI3K/Akt pathways are thought to be activated by G-CSF rodent models of muscle damage [46] and in cultured muscle cells in vitro [47]. Therefore, not surprisingly G-CSF treatment is suggested as a potential therapeutic target for a wide range of diseases outside the hematopoietic system.

\section{G-CSF/G-CSFR Outside the Hematopoietic System}

Expression of the G-CSFR is predominantly in cells of the hematopoietic system with the highest expression in neutrophils $[48,49]$. G-CSF is well known as a hematopoietic cytokine that stimulates the proliferation, differentiation, and function of myeloid progenitors and mobilization of hematopoietic stem and progenitor cells $[48,49]$. In recent years, G-CSFR expression has been identified on cells outside the hematopoietic system $[24,48]$, indicating a much wider role. G-CSFR is expressed on glial cells during neural development [50], and G-CSF has shown therapeutic benefits in neural tissue $[43,51,52]$. Rat cortical neural cells were protected against apoptotic death in vitro following G-CSF 
treatment [43]. G-CSF attenuated apoptotic death and improved the functional outcome in experimental models of spinal cord injury [53, 54] and motor function and life expectancy in the SOD1 (G93A) transgenic mouse, a rodent model for amyotrophic lateral sclerosis (ALS) [55]. G-CSF treatment also improved memory in rodent models of Alzheimer's disease [56], while contributing to regenerating following ischemic stroke $[57,58]$. Similarly, the G-CSFR has been identified on cardiomyocytes and G-CSF stimulates cardiac myocyte proliferation during mouse development [59]. Improvements in cardiac function and cardiomyocyte survival following an experimental myocardial infarct in rodents were observed with G-CSF treatment [44].

Numerous clinical trials have been completed in patients following acute myocardial infarction [60]. While early studies showed significant improvements in left ventricular end-diastolic volume and ejection volume [61, 62], others have not $[63,64]$. Meta-analysis was unable to elicit a clear answer as to the benefits of G-CSF following cardiac damage [65] but the beneficial effects of G-CSF continue to dominate the literature. Similarly, a small clinical trial demonstrated improved neurological function in stroke patients when administered G-CSF [57], while stage IIa clinical trials established that G-CSF was safe at high doses for stroke victims [66]. However, a larger stage IIb clinical trial concluded that G-CSF did not impart positive effects on stroke victims when administered intravenously $\leq 9$ hours poststroke onset [67].

\section{The Role of G-CSF in Skeletal Muscle}

G-CSF is a well-established and well-tolerated therapeutic drug, with a growing dogma that it is beneficial in the context of repair and regeneration outside the hematopoietic system. Recently, there is growing evidence for G-CSF treatment of skeletal muscle myopathies. However, conflicting results suggest that there is still much to understand before G-CSF can be considered as a therapeutic drug in the context skeletal muscle.

Muscle injury, including that caused by strenuous exercise, is associated with an increase in plasma G-CSF. For example, maximal treadmill exercise in elite winter-sport athletes, marathon running, concentric and eccentric endurance treadmill running, and moderate and intense resistance exercise all increase circulating G-CSF levels immediately postexercise $[68,69]$. It has been postulated that the elevated G-CSF levels following exercise play a role in neutrophil mobilization and delays exercise-induced neutrophil apoptosis, which is important for activating the innate immune response to exercise $[68,69]$. It may also act to elevate progenitor cell mobilization, which would serve to further enhance this effect. Certainly, systemic G-CSF levels are associated with progenitor cell mobilization following endurance, resistance, and eccentric exercise modalities [70].

Mice lacking the G-CSFR (G-CSFR ${ }^{-/}$) are neutropenic but otherwise develop normally and are indistinguishable from their littermates $[47,71]$. However, there is a suggestion that G-CSF is fundamental to muscle growth and development as the G-CSFR ${ }^{-1-}$ mice have smaller muscles than their wild-type littermates with the rectus femoris muscle appearing to have a smaller diameter [47]. This however is controversial, as no differences in cross-sectional area were observed [68]. G-CSF/G-CSFR being fundamental to growth and development is strengthened by the observation that muscle cells in vitro produce G-CSF in response to stretchinduced damage [72] and following inflammatory treatments such as long-chain free fatty acids [73] and lipopolysaccharide (LPS) treatment [74]. Furthermore, in mdx mice where constant degeneration and regeneration occurs, plasma levels are elevated, while local muscle G-CSF is reduced [75]. Since the G-CSF ligand/receptor binding causes internalization and degradation of the complex, it may be postulated that elevated G-CSF is providing protective signals and G-CSF administration may facilitate muscle regeneration and remodelling and/or influence substrate utilization leading to better functional outcome.

Various rodent models have been used to explore G-CSF as a therapeutic treatment for muscle regeneration. For example, G-CSF administration improves recovery after muscle crush injury, significantly increasing muscle strength in male Wistar rats [76]. This was associated with moderately decreased cell apoptosis, increased numbers of regenerating fibres, and increased satellite cell activation. Similarly, mice injected with snake venom to cause skeletal muscle necrosis had increased rates of regeneration and activation of known anabolic signalling pathways, such as Akt, in skeletal muscle following G-CSF treatment [46]. Improved muscle regeneration and increases in survival rates are observed with exogenous G-CSF treatment in a mouse model of muscular dystrophy $[77,78]$, while the rodent model of amyotrophic lateral sclerosis (ALS) had improved motor function and $55 \%$ larger muscle fibres following G-CSF treatment [55]. In future studies treating rodent models of ALS with pegfilgrastim, a long-lasting form of G-CSF attenuated inflammation and increased survival rates [79]. Therefore, exogenous G-CSF treatment may be beneficial for muscle when concentrations are elevated above physiological levels to around $40-50 \mathrm{ng} / \mathrm{ml}$ [16]. This is in contrast to the modest peak concentration physiological concentrations seen after exercise [70, 80].

In more recent human clinical trials, several studies have used G-CSF as a treatment for neuromuscular disease with promising results for muscle-related functional outcomes. Specifically, Sakuma et al. [81] and Yamazaki et al. [82] demonstrated improved neurological function after treatment with $10 \mu \mathrm{g} / \mathrm{kg} \mathrm{G-CSF}$ in subjects with thoracic myelopathy. This is in line with this group's previous work [83, 84] where improvements in motor function following spinal cord injuries in rodents were observed. Kato et al. [85] demonstrated reduced pain in patients with compression myelopathy. Furthermore, improved functional outcomes and independence after treatment with low-dose G-CSF were observed in a single patient with a cervical spinal injury resulting in tetraplegia [86]. Finally, improved upper limb muscle strength and reduced lower limb spasticity were observed in a patient with kyphoscoliosis [87]. It is promising to consider that G-CSF may actually be affecting the skeletal muscle and thus leading to functional improvements. But given these, disease conditions have significant involvement 
of neuronal pathways, and G-CSF is a known neuroprotective drug; it is also plausible that G-CSF acts on the nerves without directly affecting the muscle tissue.

4.1. G-CSF Signalling in Skeletal Muscle. In 2009, Naito et al. [46] used a snake venom method to induce muscle damage. Three days prior, and for 5 days following the snake venom, G-CSF was administered. Increased muscle regeneration was observed by an increase in myogenic satellite cells. Interestingly, this study also demonstrated that the Akt/GSK-3 $\beta$ signalling pathways were activated, alluding to the possibility of muscle regeneration being facilitated by intracellular signalling pathways of the G-CSFR in skeletal muscle. In 2011, bone marrow crossover transplants with G-CSFR ${ }^{-/-}$ mice demonstrated that bone marrow cells did not contribute to G-CSF-mediated muscle regeneration [47], suggesting a direct effect of G-CSF on skeletal muscle tissue. These studies suggested that G-CSF acts directly via its receptor in skeletal muscle and activated the downstream signalling pathways important for skeletal muscle growth and development. This prompted investigations into the possibility of a functional G-CSFR in satellite cells and mature skeletal muscle.

One study demonstrated expression of G-CSFR in mouse C2C12 myoblasts by Western blot and immunohistochemistry, with decreased levels during differentiation [47]. However, the specificity of the antibody used has been called into question by others [88]. Using RT-PCR, followed by sequencing of the PCR product, we identified the expression of G-CSFR mRNA in myoblasts and differentiated myotubes and mature muscle of human and murine origin [75]. Furthermore, we used Western blotting techniques with appropriate positive and negative controls, to confirm the presence of multiple glycosylated forms of G-CSFR protein [75] and observations consistent with studies in hematopoietic cells [89]. Therefore, we conclude that the G-CSFR is expressed in skeletal muscle.

It is important to address whether G-CSF does in fact ligate with the G-CSFR and activate intracellular signalling pathways for the G-CSFR in skeletal muscle. Known G-CSF signalling pathways such Jak/STAT, PI3K/Akt, and mitogen-activated protein kinases (MAPK) signalling pathways are known to be important for skeletal muscle. For example, STAT3, the most widely studied G-CSF signalling pathway, has been implicated in $\mathrm{C} 2 \mathrm{C} 12$ myoblast proliferation $[90,91]$ and in the regeneration of rodent skeletal muscle in vivo [92]. Furthermore, STAT3 signalling via JAK1 prevented premature differentiation of C2C12 myoblasts [93], while STAT3 signalling via JAK2 positively regulated C2C12 differentiation [94]. Therefore, G-CSF's role in muscle cell proliferation versus differentiation could differ depending on the Jak activated. For example, chemical inhibition of Jak2 downregulates the transcription factors myoD and MEF2, and target knockdown of Jak2 by siRNA leads to downregulated myoD and MEF2 target gene transcription [94]. In contrast, siRNA-targeted knockdown of Jak1 increased myoD and MEF2 as well as MEF2 target genes [93]. Interestingly, the few studies that have conducted signalling experiments in muscle cells when treated with
G-CSF have not measured Jak activation rather have focused their attention on downstream targets, predominantly STAT3 signalling.

Downstream of Jak-STAT signalling, Akt is activated by a distinct region of the G-CSFR upon G-CSF ligation in hematopoietic cells [95], and Akt is one of the most widely studied protein kinases in skeletal muscle biology. Expression of constitutively active Akt1 in mouse skeletal muscle increased myofibre hypertrophy and muscle mass $[37,96]$, whereas inhibition of Akt resulted in muscle atrophy [97, 98]. Moreover, homozygous dominant-negative Akt1 mice exhibit growth retardation during development, with significantly reduced body mass and a reduced lifespan [97]. For muscle cells, Akt activation via Jak2-STAT3-PI3K by G-CSF would presumably increase proliferation. Similarly, Erk1/2 activation by G-CSF leads to increased proliferation of the leukemia cell line AML-193 via a Jak2-dependent pathway [99]. In mouse myoblasts, ERK signalling positively regulates proliferation as inhibition of ERK2 blocks the G1 to $S$ phase transition promoting differentiation [100]. Therefore, G-CSF activation of Jak2-STAT3 could activate ERK signalling leading to muscle cell proliferation.

Unfortunately, the direct action of G-CSF on skeletal muscle cells and its signalling pathways remains equivocal (Figure 1). Conflicting evidence exists in C2C12 myoblasts and myotubes with one study showing that G-CSF increases myoblast proliferation and activates STAT3, Akt, and Erk1/2 [47] which supports the notion that G-CSF has a direct effect on skeletal muscle cells (Figure 2(a)). In contrast, we observed no change in proliferation of $\mathrm{C} 2 \mathrm{C} 12$ myoblasts with G-CSF concentrations between $400 \mathrm{pg} / \mathrm{ml}-100 \mathrm{ng} / \mathrm{ml}$ [75], with changes in phosphorylation of STAT3, Akt, and Erk1/ 2 attributed to media replenishment and not to the effect of G-CSF [75]. The concentrations used by Hara et al. [47] $(<375 \mathrm{pg} / \mathrm{ml})$ were significantly lower than those of Wright et al. [75] (400 pg/ml-100 ng/ml), and similarly much lower than the dose used in cell lines with a high expression of the G-CSFR [44, 101, 102]. Furthermore, the results produced by Hara et al. [47] are consistent with media changes observed in Wright et al. [75]. Unfortunately the methods used by Hara et al. [47] are ambiguous in that it is not clear whether the G-CSF was administered with or without fresh media, and no time point controls were presented. Therefore, these results should be interpreted with caution and it is likely that G-CSF does not activate these signalling pathways in healthy muscle cell in vivo. A null effect of G-CSF despite a functional receptor is consistent with M-CSF where despite the presence of the receptor in skeletal muscle cells, M-CSF has failed to elicit a direct biological effect [103]. Therefore, healthy cells may not respond to G-CSF treatment and cells may need to be under stress for G-CSFR to translocate to the cell surface (Figure 2(b)). This is supported by our studies in $\mathrm{C} 2 \mathrm{C} 12$ myotubes that have shown G-CSF treatment can augment LPS-mediated IL-6 production [74] and partially alleviate the dexamethasone-induced catabolic environment [104], with no effect on the non-LPS treated cells. Therefore, G-CSF/G-CSFR signalling may in fact require an inflammatory or catabolic state in skeletal muscle to be functional. Interestingly, IL- $6^{-/-}$macrophages produce 


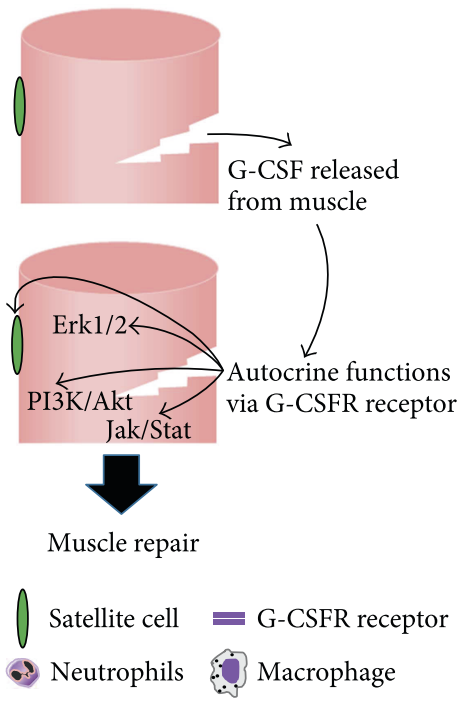

(a)

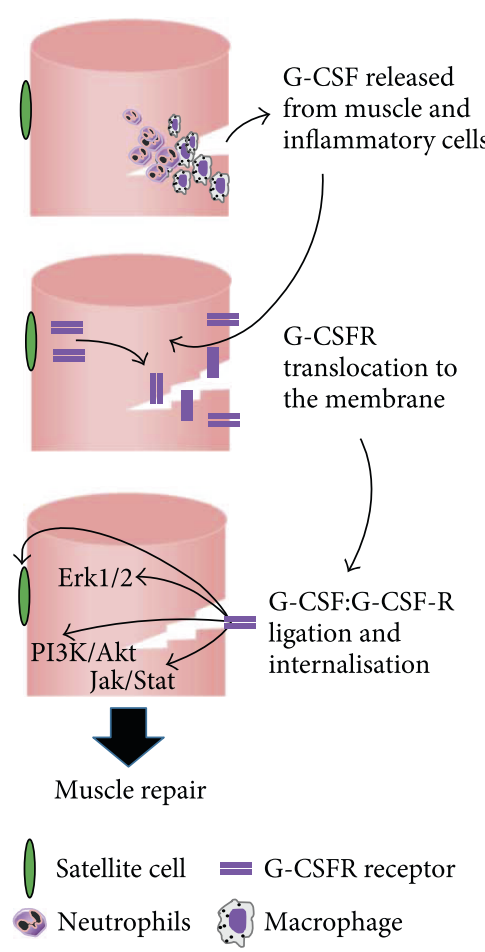

(b)
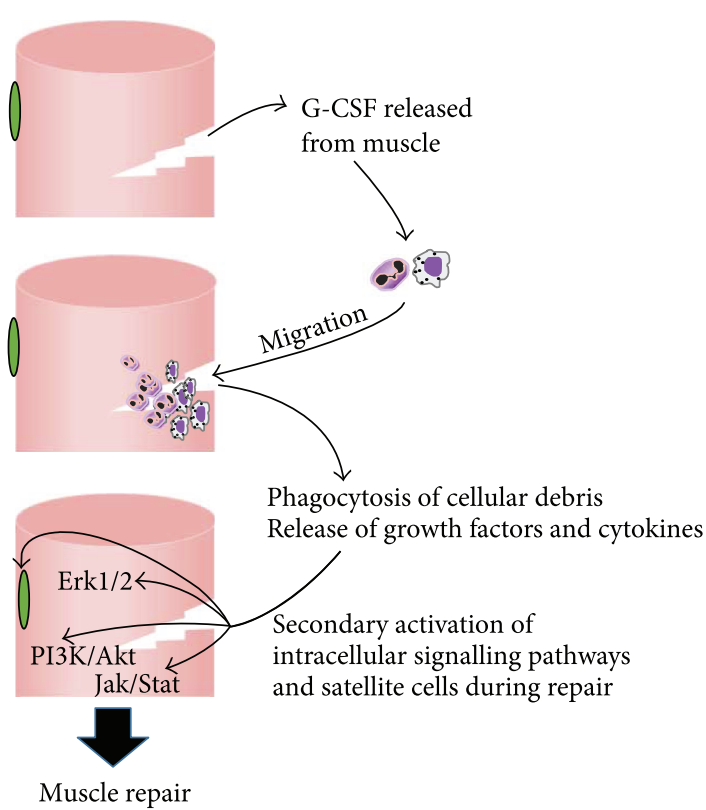

Satellite cell $=$ G-CSFR receptor
Neutrophils $\$$ Macrophage

(c)

Figure 2: Schematic representation for the plausible mechanisms by which G-CSF aids in muscle repair.

less G-CSF [105]. IL-6 $6^{-/-}$macrophages are associated with a decrease in myoblast proliferation and muscle regeneration in vivo and it is intriguing to suggest the reduced G-CSF production is contributing to this response. A third possibility is that G-CSF does not directly stimulate muscle cells. Certainly, all the rodent preclinical and human clinical trials showing improved function with G-CSF treatment are inflammatory and/or catabolic in nature and it is plausible that G-CSF influences inflammatory cells known to contribute to the repair process (Figure 2(c)).

\section{Conclusion and Future Directions}

The application of exogenous G-CSF treatment related to skeletal muscle has recently been explored, and a growing number of studies have demonstrated beneficial effects. However, the exact role of G-CSF/G-CSFR in skeletal muscle remains unclear and future studies are needed. Indeed, whether skeletal muscle cells express a functional G-CSF-R remains controversial, in part due to specificity concerns of available antibodies. Similarly, it remains unknown if the signalling pathways are activated directly in skeletal muscle due to differing results obtained from cell culture models. Therefore, the question remains as to whether G-CSF acts directly on damaged muscle cells to improve muscle health or acts on other cells such as those of hematopoietic origin, endothelial cells, and/or neuronal cells to modulate the microenvironment to favor skeletal muscle regeneration. There is a need to unequivocally determine if the G-CSF receptor is expressed in skeletal muscle and whether ligation occurs. One possibility is to perform an immunoprecipitation assay; a technique used to determine protein-protein interaction [106]. Following this, muscle-specific knockdown of the G-CSFR should be considered to determine if G-CSFR treatment does directly influence skeletal muscle. This could be achieved through a muscle-specific inducible Cre/lox strain [107] or through the more cost-effective zebrafish using CRISPR technologies [108]. More simply, to elucidate the signalling pathways in skeletal muscle, overexpression of downstream signalling targets such as Jak1 and Jak2 may augment G-CSF biological activity in skeletal muscle cells in vitro and provide conclusive evidence that G-CSF activated G-CSFR signalling pathways in skeletal muscle.

While there are promising results for the use of G-CSF to treat skeletal muscle myopathies, G-CSF has failed to elicit beneficial effects in large clinical trials of cardiomyopathies and stroke victims. This is despite promising results from in vitro and rodent models. Skeletal muscle may be similar, in that the early promising signs from cell culture and rodent models may not translate to G-CSF being a readily available therapeutic drug for skeletal muscle. Given the current inconsistencies in muscle cell culture signalling and the cross-reactivity of the G-CSFR antibodies, we may need more evidence before G-CSF is considered as a therapeutic treatment for muscle-related diseases.

\section{Conflicts of Interest}

The authors declare that there is no conflict of interests regarding the publication of this paper. 


\section{Acknowledgments}

This manuscript is based on the work of Craig Robert Wright, "Role and Regulation of G-CSF and Its Receptor in Skeletal Muscle" (21/10/2013), PhD Thesis, Deakin University [109]. The thesis is held in Deakin University's online repository. This work was supported by the Institute for Physical Activity and Nutrition (IPAN), Deakin University, Australia. The authors would like to thank Alex Addinsall (Deakin University) for his editorial skills and artwork contribution to this manuscript.

\section{References}

[1] N. A. Nicola, D. Metcalf, G. R. Johnson, and A. W. Burgess, "Separation of functionally distinct human granulocytemacrophage colony-stimulating factors," Blood, vol. 54, no. 3, pp. 614-627, 1979.

[2] D. Metcalf and N. A. Nicola, "Proliferative effects of purified granulocyte colony-stimulating factor (G-CSF) on normal mouse hemopoietic cells," Journal of Cellular Physiology, vol. 116, no. 2, pp. 198-206, 1983.

[3] S. Nagata and R. Fukunaga, "Granulocyte colony-stimulating factor and its receptor," Progress in Growth Factor Research, vol. 3, no. 2, pp. 131-141, 1991.

[4] A. W. Roberts, "G-CSF: a key regulator of neutrophil production, but that's not all!," Growth Factor, vol. 23, no. 1, pp. 33-41, 2005.

[5] M. H. Bronchud, J. H. Scarffe, N. Thatcher et al., "Phase I/II study of recombinant human granulocyte colonystimulating factor in patients receiving intensive chemotherapy for small cell lung cancer," British Journal of Cancer, vol. 56, no. 6, pp. 809-813, 1987.

[6] H. Reikvam, U. S. Blom, E. Kristoffersen, K. Liseth, O. Bruserud, and T. Hervig, "Granulocyte transfusion," Tidsskrift for Den norske legeforening, vol. 129, no. 5, pp. 416-419, 2009.

[7] G. Lyman, A. Lalla, R. Barron, and R. W. Dubois, "Costeffectiveness of pegfilgrastim versus 6-day filgrastim primary prophylaxis in patients with non-Hodgkin's lymphoma receiving CHOP-21 in United States," Current Medical Research and Opinion, vol. 25, no. 2, pp. 401-411, 2009.

[8] E. Shochat and V. Rom-Kedar, "Novel strategies for granulocyte colony-stimulating factor treatment of severe prolonged neutropenia suggested by mathematical modeling," Clinical Cancer Research, vol. 14, no. 20, pp. 6354-6363, 2008.

[9] H. W. Tuffaha, I. M. Treish, and L. Zaru, "The use and effectiveness of granulocyte colony-stimulating factor in primary prophylaxis for febrile neutropenia in the outpatient setting," Journal Of Oncology Pharmacy Practice, vol. 14, no. 3, pp. 131-138, 2008.

[10] A. Eldar-Lissai, L. E. Cosler, E. Culakova, and G. H. Lyman, "Economic analysis of prophylactic pegfilgrastim in adult cancer patients receiving chemotherapy," Value in Health, vol. 11, no. 2, pp. 172-179, 2008.

[11] T. Y. Khrichkova, V. E. Gol'dberg, V. V. Zhdanov et al., "Mechanisms of stimulation of granulocytopoiesis with neupogen in patients with breast cancer during chemotherapy," Bulletin of Experimental Biology and Medicine, vol. 145, no. 4, pp. 467-471, 2008.
[12] M. Morishita and R. C. Leonard, "Pegfilgrastim; a neutrophil mediated granulocyte colony stimulating factor-expanding uses in cancer chemotherapy," Expert Opinion on Biological Therapy, vol. 8, no. 7, pp. 993-1001, 2008.

[13] J. de la Rubia and M. A. Sanz, "Autologous peripheral blood stem cell transplantation for acute leukaemias," Best Practice \& Research Clinical Haematology, vol. 12, no. 1-2, pp. 139150, 1999.

[14] G. J. Elfenbein, "Granulocyte-colony stimulating factor primed bone marrow and granulocyte-colony stimulating factor mobilized peripheral blood stem cells are equivalent for engraftment: which to choose?," Pediatric Transplantation, vol. 9, Supplement 7, pp. 37-47, 2005.

[15] D. L. Pitrak, "Filgrastim treatment of HIV-infected patients improves neutrophil function," AIDS, vol. 13, Supplement 2, pp. S25-S30, 1999.

[16] M. de Haas, J. M. Kerst, C. E. van der Schoot et al., "Granulocyte colony-stimulating factor administration to healthy volunteers: analysis of the immediate activating effects on circulating neutrophils," Blood, vol. 84, no. 11, pp. 38853894, 1994.

[17] D. C. Dale and T. H. Price, "Granulocyte transfusion therapy: a new era?," Current Opinion in Hematology, vol. 16, no. 1, pp. 1-2, 2009.

[18] T. H. Price, "Granulocyte transfusion: current status," Seminars in Hematology, vol. 44, no. 1, pp. 15-23, 2007.

[19] R. Fukunaga, Y. Seto, S. Mizushima, and S. Nagata, "Three different mRNAs encoding human granulocyte colonystimulating factor receptor," Proceedings of the National Academy of Sciences of the United States of America, vol. 87, no. 22, pp. 8702-8706, 1990.

[20] J. E. Layton and N. E. Hall, "The interaction of G-CSF with its receptor," Frontiers in Bioscience, vol. 11, pp. 31813189, 2006.

[21] I. P. Touw and G.-J. M. van de Geijn, "Granulocyte colonystimulating factor and its receptor in normal myeloid cell development, leukemia and related blood cell disorders," Frontiers in Bioscience, vol. 12, pp. 800-815, 2007.

[22] S. J. Baker, S. G. Rane, and E. P. Reddy, "Hematopoietic cytokine receptor signaling," Oncogene, vol. 26, no. 47, pp. 6724-6737, 2007.

[23] K. Yamasaki, S. Naito, H. Anaguchi, T. Ohkubo, and Y. Ota, "Solution structure of an extracellular domain containing the WSxWS motif of the granulocyte colony-stimulating factor receptor and its interaction with ligand," Nature Structural Biology, vol. 4, no. 6, pp. 498-504, 1997.

[24] C. Liongue, C. Wright, A. P. Russell, and A. C. Ward, "Granulocyte colony-stimulating factor receptor: stimulating granulopoiesis and much more," The International Journal of Biochemistry \& Cell Biology, vol. 41, no. 12, pp. 23722375, 2009.

[25] A. C. Ward, M. H. Hermans, L. Smith et al., "Tyrosinedependent and -independent mechanisms of STAT3 activation by the human granulocyte colony-stimulating factor (G-CSF) receptor are differentially utilized depending on G-CSF concentration," Blood, vol. 93, no. 1, pp. 113124, 1999.

[26] A. D. Panopoulos, L. Zhang, J. W. Snow et al., "STAT3 governs distinct pathways in emergency granulopoiesis and mature neutrophils," Blood, vol. 108, no. 12, pp. 36823690, 2006. 
[27] B. R. Avalos, "Molecular analysis of the granulocyte colony-stimulating factor receptor," Blood, vol. 88, no. 3, pp. 761-777, 1996.

[28] G. D. Demetri and J. D. Griffin, "Granulocyte colonystimulating factor and its receptor," Blood, vol. 78, no. 11, pp. 2791-2808, 1991.

[29] J. E. Darnell Jr., "STATs and gene regulation," Science, vol. 277, no. 5332, pp. 1630-1635, 1997.

[30] T. Decker and P. Kovarik, "Transcription factor activity of STAT proteins: structural requirements and regulation by phosphorylation and interacting proteins," Cellular and Molecular Life Sciences (CMLS), vol. 55, no. 12, pp. 15351546, 1999.

[31] A. C. Ward, L. Smith, J. P. de Koning, Y. van Aesch, and I. P. Touw, "Multiple signals mediate proliferation, differentiation, and survival from the granulocyte colony-stimulating factor receptor in myeloid 32D cells," Journal of Biological Chemistry, vol. 274, no. 21, pp. 14956-14962, 1999.

[32] A. C. Ward, Y. M. van Aesch, J. Gits et al., "Novel point mutation in the extracellular domain of the granulocyte colony-stimulating factor (G-CSF) receptor in a case of severe congenital neutropenia hyporesponsive to G-CSF treatment," The Journal of Experimental Medicine, vol. 190, no. 4, pp. 497-508, 1999.

[33] S. J. Corey, A. L. Burkhardt, J. B. Bolen, R. L. Geahlen, L. S. Tkatch, and D. J. Tweardy, "Granulocyte colony-stimulating factor receptor signaling involves the formation of a threecomponent complex with Lyn and Syk protein-tyrosine kinases," Proceedings of the National Academy of Sciences of the United States of America, vol. 91, no. 11, pp. 46834687, 1994.

[34] A. C. Ward, J. L. Monkhouse, X. F. Csar, I. P. Touw, and P. A. Bello, "The Src-like tyrosine kinase Hck is activated by granulocyte colony-stimulating factor (G-CSF) and docks to the activated G-CSF receptor," Biochemical and Biophysical Research Communications, vol. 251, no. 1, pp. 117-123, 1998.

[35] D. J. Glass, "Molecular mechanisms modulating muscle mass," Trends in Molecular Medicine, vol. 9, no. 8, pp. 344350, 2003.

[36] T. N. Stitt, D. Drujan, B. A. Clarke et al., "The IGF-1/ PI3K/Akt pathway prevents expression of muscle atrophyinduced ubiquitin ligases by inhibiting FOXO transcription factors," Molecular Cell, vol. 14, no. 3, pp. 395-403, 2004.

[37] S. C. Bodine, T. N. Stitt, M. Gonzalez et al., "Akt/mTOR pathway is a crucial regulator of skeletal muscle hypertrophy and can prevent muscle atrophy in vivo," Nature Cell Biology, vol. 3, no. 11, pp. 1014-1019, 2001.

[38] B. DeBosch, I. Treskov, T. S. Lupu et al., "Akt1 is required for physiological cardiac growth," Circulation, vol. 113, no. 17, pp. 2097-2104, 2006.

[39] T. F. Franke, D. R. Kaplan, and L. C. Cantley, "PI3K: downstream AKTion blocks apoptosis," Cell, vol. 88, no. 4, pp. 435-437, 1997.

[40] K. Inoki, Y. Li, T. Zhu, J. Wu, and K.-L. Guan, "TSC2 is phosphorylated and inhibited by Akt and suppresses mTOR signalling," Nature Cell Biology, vol. 4, no. 9, pp. 648-657, 2002.

[41] K. Kamezaki, K. Shimoda, A. Numata et al., "Roles of Stat3 and ERK in G-CSF signaling," Stem Cells, vol. 23, no. 2, pp. 252-263, 2005.

[42] M. Frodin and S. Gammeltoft, "Role and regulation of $90 \mathrm{kDa}$ ribosomal S6 kinase (RSK) in signal transduction,"
Molecular and Cellular Endocrinology, vol. 151, no. 1-2, pp. 65-77, 1999.

[43] A. Schneider, C. Kruger, T. Steigleder et al., "The hematopoietic factor G-CSF is a neuronal ligand that counteracts programmed cell death and drives neurogenesis," The Journal of Clinical Investigation, vol. 115, no. 8, pp. 20832098, 2005.

[44] M. Harada, Y. Qin, H. Takano et al., "G-CSF prevents cardiac remodeling after myocardial infarction by activating the Jak-Stat pathway in cardiomyocytes," Nature Medicine, vol. 11, no. 3, pp. 305-311, 2005.

[45] Y. Li, G. Takemura, H. Okada et al., "Treatment with granulocyte colony-stimulating factor ameliorates chronic heart failure," Laboratory Investigation, vol. 86, no. 1, pp. 32-44, 2006.

[46] T. Naito, K. Goto, S. Morioka et al., "Administration of granulocyte colony-stimulating factor facilitates the regenerative process of injured mice skeletal muscle via the activation of Akt/GSK $3 \alpha \beta$ signals," European Journal of Applied Physiology, vol. 105, no. 4, pp. 643-651, 2009.

[47] M. Hara, S. Yuasa, K. Shimoji et al., "G-CSF influences mouse skeletal muscle development and regeneration by stimulating myoblast proliferation," The Journal of Experimental Medicine, vol. 208, no. 4, pp. 715-727, 2011.

[48] P. Anderlini, "Effects and safety of granulocyte colonystimulating factor in healthy volunteers," Current Opinion in Hematology, vol. 16, no. 1, pp. 35-40, 2009.

[49] P. Anderlini, D. Przepiorka, R. Champlin, and M. Körbling, "Biologic and clinical effects of granulocyte colonystimulating factor in normal individuals," Blood, vol. 88, no. 8, pp. 2819-2825, 1996.

[50] F. Kirsch, C. Kruger, and A. Schneider, "The receptor for granulocyte-colony stimulating factor (G-CSF) is expressed in radial glia during development of the nervous system," BMC Developmental Biology, vol. 8, no. 1, p. 32, 2008.

[51] I. Solaroglu, V. Jadhav, and J. H. Zhang, "Neuroprotective effect of granulocyte-colony stimulating factor," Frontiers in Bioscience, vol. 12, pp. 712-724, 2007.

[52] J. Wang, L. Yao, S. Zhao et al., "Granulocyte-colony stimulating factor promotes proliferation, migration and invasion in glioma cells," Cancer Biology \& Therapy, vol. 13, no. 6, pp. 389-400, 2012.

[53] C. Pitzer, S. Klussmann, C. Krüger et al., "The hematopoietic factor granulocyte-colony stimulating factor improves outcome in experimental spinal cord injury," Journal of Neurochemistry, vol. 113, no. 4, pp. 930-942, 2010.

[54] Y. Nishio, M. Koda, T. Kamada et al., "Granulocyte colonystimulating factor attenuates neuronal death and promotes functional recovery after spinal cord injury in mice," Journal of Neuropathology and Experimental Neurology, vol. 66, no. 8, pp. 724-731, 2007.

[55] C. Pitzer, C. Kruger, C. Plaas et al., "Granulocyte-colony stimulating factor improves outcome in a mouse model of amyotrophic lateral sclerosis," Brain, vol. 131, no. 12, pp. 3335-3347, 2008.

[56] K. J. Tsai, Y. C. Tsai, and C. K. Shen, "G-CSF rescues the memory impairment of animal models of Alzheimer's disease," The Journal of Experimental Medicine, vol. 204, no. 6, pp. 1273-1280, 2007.

[57] W. C. Shyu, S. Z. Lin, C. C. Lee, D. D. Liu, and H. Li, "Granulocyte colony-stimulating factor for acute ischemic 
stroke: a randomized controlled trial," Canadian Medical Association Journal, vol. 174, no. 7, pp. 927-933, 2006.

[58] I. Solaroglu, J. Cahill, V. Jadhav, and J. H. Zhang, "A novel neuroprotectant granulocyte-colony stimulating factor," Stroke, vol. 37, no. 4, pp. 1123-1128, 2006.

[59] K. Shimoji, S. Yuasa, T. Onizuka et al., "G-CSF promotes the proliferation of developing cardiomyocytes in vivo and in derivation from ESCs and iPSCs," Cell Stem Cell, vol. 6, no. 3, pp. 227-237, 2010.

[60] H. Takano, K. Ueda, H. Hasegawa, and I. Komuro, "G-CSF therapy for acute myocardial infarction," Trends in Pharmacological Sciences, vol. 28, no. 10, pp. 512-517, 2007.

[61] M. Valgimigli, G. M. Rigolin, C. Cittanti et al., "Use of granulocyte-colony stimulating factor during acute myocardial infarction to enhance bone marrow stem cell mobilization in humans: clinical and angiographic safety profile," European Heart Journal, vol. 26, no. 18, pp. 1838-1845, 2005.

[62] K. Suzuki, K. Nagashima, M. Arai et al., "Effect of granulocyte colony-stimulating factor treatment at a low dose but for a long duration in patients with coronary heart disease," Circulation Journal, vol. 70, no. 4, pp. 430-437, 2006.

[63] S. G. Ellis, M. S. Penn, B. Bolwell et al., "Granulocyte colony stimulating factor in patients with large acute myocardial infarction: results of a pilot dose-escalation randomized trial," American Heart Journal, vol. 152, no. 6, pp. 1051.e91051.e14, 2006.

[64] R. S. Ripa, E. Jorgensen, Y. Wang et al., "Stem cell mobilization induced by subcutaneous granulocyte-colony stimulating factor to improve cardiac regeneration after acute ST-elevation myocardial infarction: result of the doubleblind, randomized, placebo-controlled stem cells in myocardial infarction (STEMMI) trial," Circulation, vol. 113, no. 16, pp. 1983-1992, 2006.

[65] A. Abdel-Latif, R. Bolli, E. K. Zuba-Surma, I. M. Tleyjeh, C. A. Hornung, and B. Dawn, "Granulocyte colony-stimulating factor therapy for cardiac repair after acute myocardial infarction: a systematic review and meta-analysis of randomized controlled trials," American Heart Journal, vol. 156, no. 2, pp. 216-226.e9, 2008.

[66] W. R. Schabitz, R. Laage, G. Vogt et al., "AXIS: a trial of intravenous granulocyte colony-stimulating factor in acute ischemic stroke," Stroke, vol. 41, no. 11, pp. 2545-2551, 2010.

[67] E. B. Ringelstein, V. Thijs, B. Norrving et al., "Granulocyte colony-stimulating factor in patients with acute ischemic stroke: results of the AX200 for ischemic stroke trial," Stroke, vol. 44, no. 10, pp. 2681-2687, 2013.

[68] M. Yamada, K. Suzuki, S. Kudo, M. Totsuka, S. Nakaji, and K. Sugawara, "Raised plasma G-CSF and IL-6 after exercise may play a role in neutrophil mobilization into the circulation," Journal of Applied Physiology, vol. 92, no. 5, pp. 1789-1794, 2002.

[69] F. C. Mooren, K. Volker, R. Klocke, S. Nikol, J. Waltenberger, and K. Kruger, "Exercise delays neutrophil apoptosis by a G-CSF-dependent mechanism," Journal of Applied Physiology, vol. 113, no. 7, pp. 1082-1090, 2012.

[70] K. Kruger, C. Pilat, M. Schild et al., "Progenitor cell mobilization after exercise is related to systemic levels of G-CSF and muscle damage," Scandinavian Journal of Medicine \& Science in Sports, vol. 25, no. 3, pp. e283-e291, 2015.

[71] F. Liu, H. Y. Wu, R. Wesselschmidt, T. Kornaga, and D. C. Link, "Impaired production and increased apoptosis of neutrophils in granulocyte colony-stimulating factor receptor-deficient mice," Immunity, vol. 5, no. 5, pp. 491501, 1996.

[72] J. M. Peterson and F. X. Pizza, "Cytokines derived from cultured skeletal muscle cells after mechanical strain promote neutrophil chemotaxis in vitro," Journal of Applied Physiology, vol. 106, no. 1, pp. 130-137, 2009.

[73] A. M. Ordelheide, N. Gommer, A. Bohm et al., "Granulocyte colony-stimulating factor (G-CSF): a saturated fatty acidinduced myokine with insulin-desensitizing properties in humans," Molecular Metabolism, vol. 5, no. 4, pp. 305316, 2016.

[74] C. R. Wright, E. L. Brown, P. A. Della Gatta et al., "Regulation of granulocyte colony-stimulating factor and its receptor in skeletal muscle is dependent upon the type of inflammatory stimulus," Journal of Interferon \& Cytokine Research, vol. 35, no. 9, pp. 710-9, 2015.

[75] C. R. Wright, E. L. Brown, P. A. Della Gatta, A. C. Ward, G. S. Lynch, and A. P. Russell, "G-CSF does not influence $\mathrm{C} 2 \mathrm{C} 12$ myogenesis despite receptor expression in healthy and dystrophic skeletal muscle," Frontiers in Physiology, vol. 5, p. 170, 2014.

[76] I. Stratos, R. Rotter, C. Eipel, T. Mittlmeier, and B. Vollmar, "Granulocyte-colony stimulating factor enhances muscle proliferation and strength following skeletal muscle injury in rats," Journal Of Applied Physiology, vol. 103, no. 5, pp. 1857-1863, 2007.

[77] N. Hayashiji, S. Yuasa, Y. Miyagoe-Suzuki et al., "G-CSF supports long-term muscle regeneration in mouse models of muscular dystrophy," Nature Communications, vol. 6, p. $6745,2015$.

[78] G. F. Simoes, S. U. Benitez, and A. L. Oliveira, "Granulocyte colony-stimulating factor (G-CSF) positive effects on muscle fiber degeneration and gait recovery after nerve lesion in MDX mice," Brain and Behavior, vol. 4, no. 5, pp. 738753, 2014.

[79] E. Pollari, E. Savchenko, M. Jaronen et al., "Granulocyte colony stimulating factor attenuates inflammation in a mouse model of amyotrophic lateral sclerosis," Journal of Neuroinflammation, vol. 8, no. 1, p. 74, 2011.

[80] F. C. Mooren and K. Kruger, "Apoptotic lymphocytes induce progenitor cell mobilization after exercise," Journal of Applied Physiology, vol. 119, no. 2, pp. 135-139, 2015.

[81] T. Sakuma, M. Yamazaki, A. Okawa et al., "Neuroprotective therapy using granulocyte colony-stimulating factor for patients with worsening symptoms of thoracic myelopathy: a multicenter prospective controlled trial," Spine, vol. 37, no. 17, pp. 1475-1478, 2012.

[82] M. Yamazaki, T. Sakuma, K. Kato, T. Furuya, and M. Koda, "Granulocyte colony-stimulating factor reduced neuropathic pain associated with thoracic compression myelopathy: report of two cases," The Journal of Spinal Cord Medicine, vol. 36, no. 1, pp. 40-43, 2013.

[83] K. Kato, M. Koda, H. Takahashi et al., "Granulocyte colonystimulating factor attenuates spinal cord injury-induced mechanical allodynia in adult rats," Journal of the Neurological Sciences, vol. 355, no. 1-2, pp. 79-83, 2015.

[84] K. Kamiya, M. Koda, T. Furuya et al., "Neuroprotective therapy with granulocyte colony-stimulating factor in acute spinal cord injury: a comparison with high-dose methylprednisolone as a historical control," European Spine Journal, vol. 24, no. 5, pp. 963-967, 2015. 
[85] K. Kato, M. Yamazaki, A. Okawa et al., "Intravenous administration of granulocyte colony-stimulating factor for treating neuropathic pain associated with compression myelopathy: a phase I and IIa clinical trial," European Spine Journal, vol. 22, no. 1, pp. 197-204, 2013.

[86] B. Okurowska-Zawada, W. Kulak, D. Sienkiewicz et al., "Safety and efficacy of granulocyte colony stimulating factor in a patient with tetraplegia caused by cervical hyperextension injury: a case report," Progress in Health Sciences, vol. 4, no. 2, pp. 181-184, 2014.

[87] D. Sienkiewicz, W. Kulak, B. Okurowska-Zawada et al., "Potential beneficial effects of granulocyte colonystimulating factor therapy for spastic paraparesis in a patient with kyphoscoliosis: a case report," Neuropediatrics, vol. 45, no. 05, pp. 325-327, 2014.

[88] C. deBruin, P. Lincoln, C. Hartley, A. Shehabeldin, G. Van, and S. J. Szilvassy, "Most purported antibodies to the human granulocyte colony-stimulating factor receptor are not specific," Experimental Hematology, vol. 38, no. 11, pp. 1022-1035, 2010.

[89] M. H. Hermans, A. C. Ward, C. Antonissen, A. Karis, B. Lowenberg, and I. P. Touw, "Perturbed granulopoiesis in mice with a targeted mutation in the granulocyte colonystimulating factor receptor gene associated with severe chronic neutropenia," Blood, vol. 92, no. 1, pp. 32-39, 1998.

[90] L. A. Megeney, R. L. Perry, J. E. LeCouter, and M. A. Rudnicki, "bFGF and LIF signaling activates STAT3 in proliferating myoblasts," Developmental Genetics, vol. 19, no. 2, pp. 139-145, 1996.

[91] E. E. Spangenburg and F. W. Booth, "Multiple signaling pathways mediate LIF-induced skeletal muscle satellite cell proliferation," American Journal of Physiology Cell Physiology, vol. 283, no. 1, pp. C204-C211, 2002.

[92] K. Kami and E. Senba, "In vivo activation of STAT3 signaling in satellite cells and myofibers in regenerating rat skeletal muscles," The Journal of Histochemistry and Cytochemistry, vol. 50, no. 12, pp. 1579-1589, 2002.

[93] L. Sun, K. Ma, H. Wang et al., "JAK1-STAT1-STAT3, a key pathway promoting proliferation and preventing premature differentiation of myoblasts," The Journal of Cell Biology, vol. 179, no. 1, pp. 129-138, 2007.

[94] K. Wang, C. Wang, F. Xiao, H. Wang, and Z. Wu, "JAK2/ STAT2/STAT3 are required for myogenic differentiation," Journal of Biological Chemistry, vol. 283, no. 49, pp. 3402934036, 2008.

[95] F. Dong and A. C. Larner, "Activation of Akt kinase by granulocyte colony-stimulating factor (G-CSF): evidence for the role of a tyrosine kinase activity distinct from the Janus kinases," Blood, vol. 95, no. 5, pp. 1656-1662, 2000.

[96] K.-M. V. Lai, M. Gonzalez, W. T. Poueymirou et al., "Conditional activation of akt in adult skeletal muscle induces rapid hypertrophy," Molecular and Cellular Biology, vol. 24, no. 21, pp. 9295-9304, 2004.

[97] W. S. Chen, P. Z. Xu, K. Gottlob et al., "Growth retardation and increased apoptosis in mice with homozygous disruption of the Akt1 gene," Genes \& Development, vol. 15, no. 17, pp. 2203-2208, 2001.

[98] H. Cho, J. Mu, J. K. Kim et al., "Insulin resistance and a diabetes mellitus-like syndrome in mice lacking the protein kinase Akt2 (PKB $\beta)$," Science, vol. 292, no. 5522, pp. 1728$1731,2001$.
[99] L. Wang, J. Xue, E. V. Zadorozny, and L. J. Robinson, “G-CSF stimulates Jak2-dependent Gab2 phosphorylation leading to Erk1/2 activation and cell proliferation," Cellular Signalling, vol. 20, no. 10, pp. 1890-1899, 2008.

[100] N. C. Jones, Y. V. Fedorov, R. S. Rosenthal, and B. B. Olwin, "ERK1/2 is required for myoblast proliferation but is dispensable for muscle gene expression and cell fusion," Journal of Cellular Physiology, vol. 186, no. 1, pp. 104-115, 2001.

[101] O. Tura, J. Crawford, G. R. Barclay et al., "Granulocyte colony-stimulating factor (G-CSF) depresses angiogenesis in vivo and in vitro: implications for sourcing cells for vascular regeneration therapy," Journal of Thrombosis and Haemostasis, vol. 8, no. 7, pp. 1614-1623, 2010.

[102] T. S. Kendrick, R. J. Lipscombe, O. Rausch et al., "Contribution of the membrane-distal tyrosine in intracellular signaling by the granulocyte colony-stimulating factor receptor," Journal of Biological Chemistry, vol. 279, no. 1, pp. 326-340, 2004.

[103] N. A. Dumont and J. Frenette, "Macrophage colonystimulating factor-induced macrophage differentiation promotes regrowth in atrophied skeletal muscles and C2C12 myotubes," The American Journal of Pathology, vol. 182, no. 2, pp. 505-515, 2013.

[104] C. R. Wright, E. L. Brown, A. C. Ward, and A. P. Russell, "G-CSF treatment can attenuate dexamethasone-induced reduction in $\mathrm{C} 2 \mathrm{C} 12$ myotube protein synthesis," Cytokine, vol. 73, no. 1, pp. 1-7, 2015.

[105] C. Zhang, Y. Li, Y. Wu, L. Wang, X. Wang, and J. Du, "Interleukin-6/signal transducer and activator of transcription 3 (STAT3) pathway is essential for macrophage infiltration and myoblast proliferation during muscle regeneration," Journal of Biological Chemistry, vol. 288, no. 3, pp. 14891499, 2013.

[106] M. Monti, M. Cozzolino, F. Cozzolino, R. Tedesco, and P. Pucci, "Functional proteomics: protein-protein interactions in vivo," The Italian Journal of Biochemistry, vol. 56, no. 4, pp. 310-4, 2007.

[107] J. J. McCarthy, R. Srikuea, T. J. Kirby, C. A. Peterson, and K. A. Esser, "Inducible Cre transgenic mouse strain for skeletal muscle-specific gene targeting," Skeletal Muscle, vol. 2, no. 1, p. 8, 2012.

[108] J. Liu, Y. Zhou, X. Qi et al., "CRISPR/Cas9 in zebrafish: an efficient combination for human genetic diseases modeling," Human Genetics, vol. 136, no. 1, pp. 1-12, 2017.

[109] C. Wright, Role and Regulation of G-CSF and Its Receptor in Skeletal Muscle, [Ph.D. thesis], Deakin Univerity, 2013. 


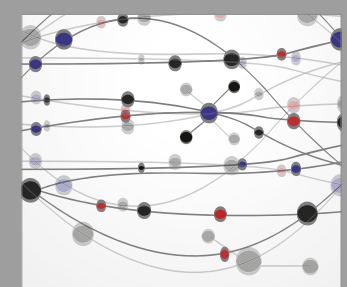

The Scientific World Journal
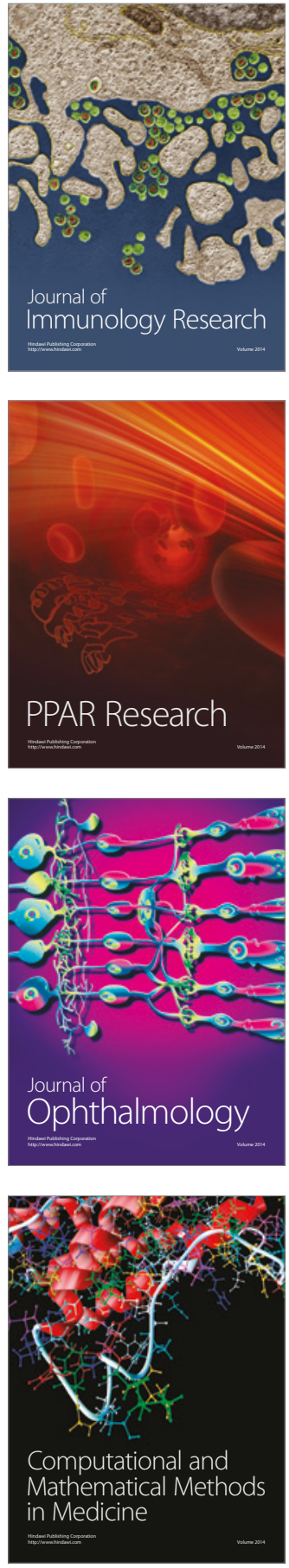

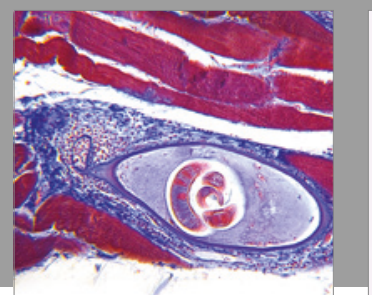

Gastroenterology Research and Practice
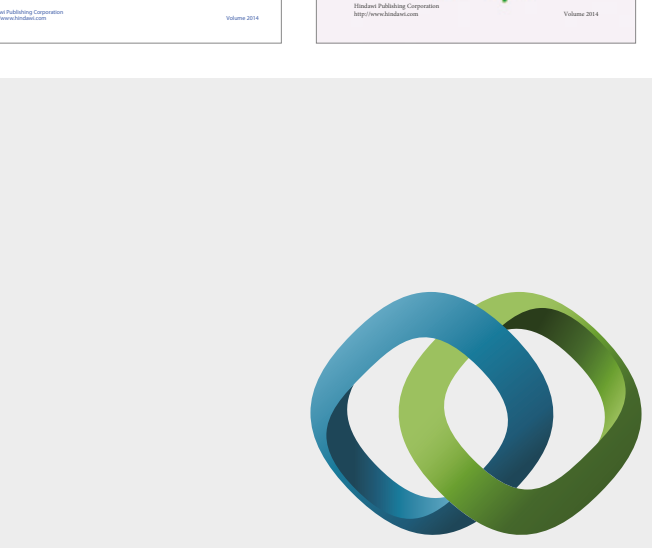

\section{Hindawi}

Submit your manuscripts at

https://www.hindawi.com
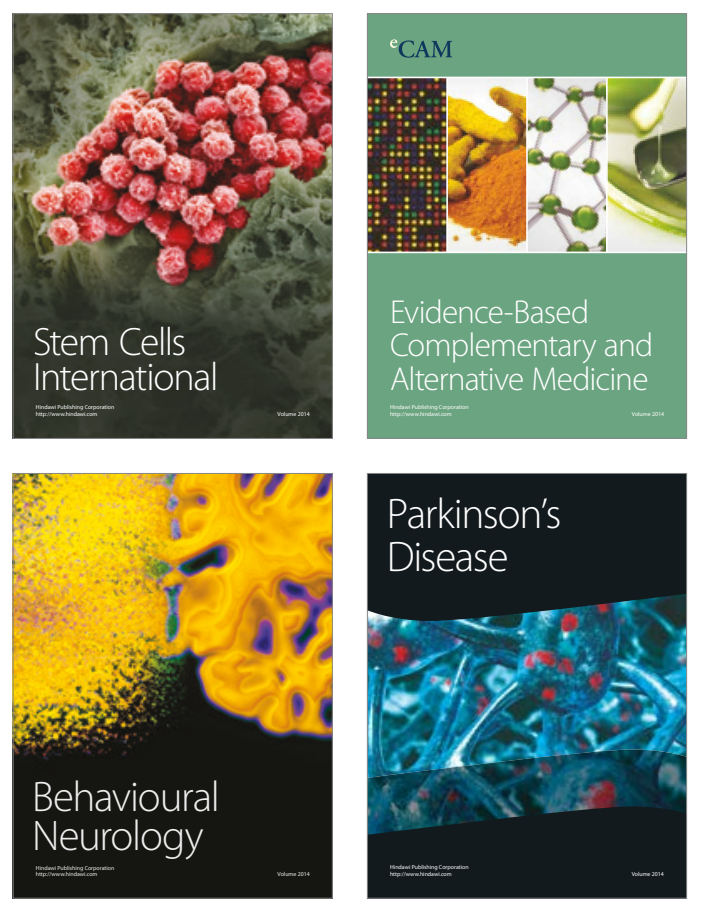
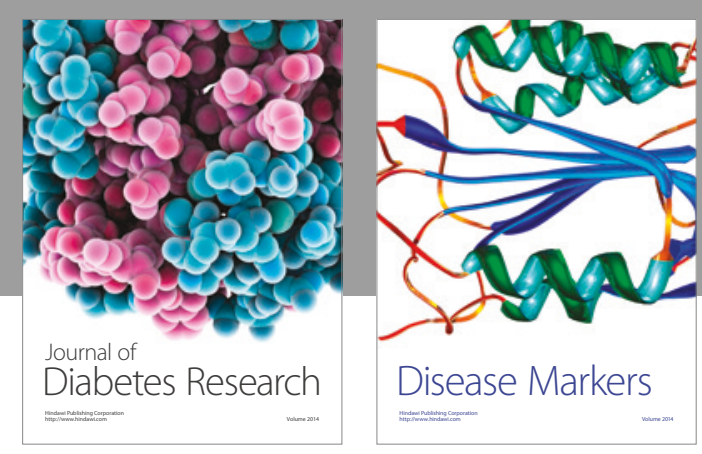

Disease Markers
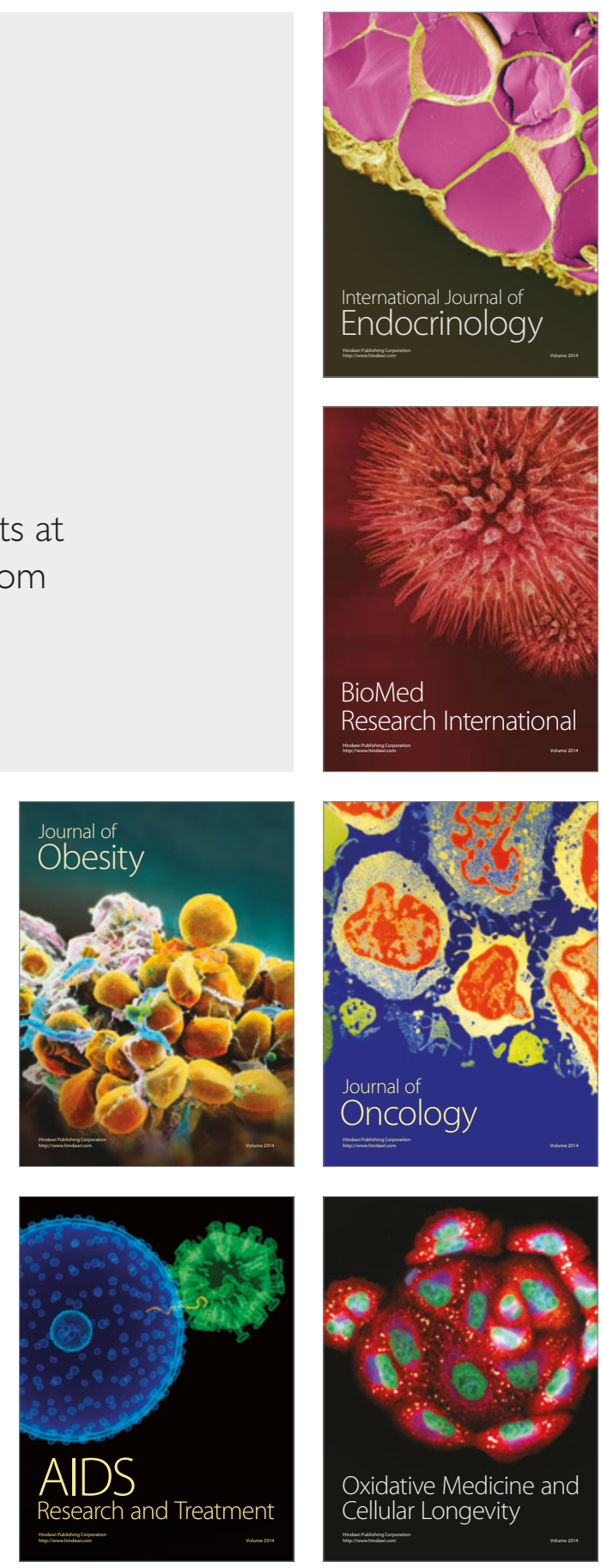